\title{
Implicit vs. Explicit Incentives: Theory and a Case Study
}

\author{
DOMINIQUE DEMOUGIN \\ OLIVER FABEL \\ CHRISTIAN THOMANN
}

\section{CESIFO WORKING PAPER NO. 2645 \\ CATEGORY 4: LABOUR MARKETS \\ MAY 2009}

Presented at CESifo Area Conference on ApPlied Microeconomics, March 2009

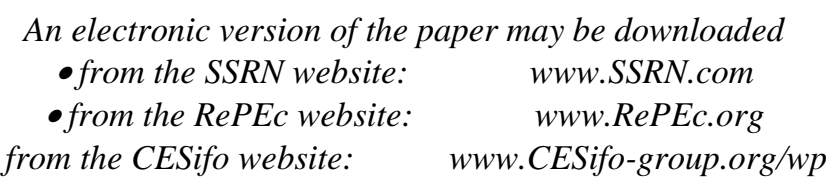




\title{
Implicit vs. Explicit Incentives: Theory and a Case Study
}

\begin{abstract}
We derive the optimal contract between a principal and a liquidity-constrained agent in a stochastically repeated environment. The contract comprises a court-enforceable explicit bonus rule and an implicit fixed salary promise that must be self-enforcing. Since the agent's rent increases with bonus pay, the principal implements the maximum credible salary promise. Thus, the bonus increases while the salary promise and the agent's effort decrease with a higher probability of premature contract termination. We subject this mechanism to econometric testing using personnel data of an insurance company. The empirical results strongly support our theoretical predictions.
\end{abstract}

JEL Code: J3, M5.

Keywords: implicit contract, explicit bonus pay, premature contract termination, compensation and productivity estimates.

Dominique Demougin
Department of Law, Governance and Economics
European Business School
International University Schloß Reichartshausen
Rheingaustrasse 1
Germany - 65375 Oestrich-Winkel
dominique.demougin@ebs.de

Oliver Fabel

Department of Business Administration

University of Vienna

Brünner Strasse 72

Austria - 1210 Vienna

oliver.fabel@univie.ac.at

\author{
Christian Thomann \\ Institute for Insurance Economics \\ University of Hannover \\ Königsworther Platz 1 \\ Germany - 30167 Hannover \\ ct@ivbl.uni-hannover.de
}

May 4, 2009

The first author acknowledges financial support by the German Research Council (DFG: DE1169/1-1). We are grateful for helpful comments from the participants of the 2009 CesIfo Conference on Applied Microeconomics in Munich, the 2009 Colloquium on Personnel Economics in Vienna, and by our colleagues P. Belleflamme and R. Gropp. 


\section{Introduction}

We examine a contracting problem in a stochastically repeated environment between a risk-neutral principal and an agent that is risk-neutral but liquidity constrained. The agent's effort is assumed observable albeit not contractible. In such an environment, the incentive scheme may comprise two parts. Contingent on the realization of a verifiable - i. e. court-enforceable - monitoring signal, the principal can offer an explicit bonus. In addition, he can condition a salary promise on the observation that the agent's effort satisfies an implicitly agreed threshold level. Since the agent's effort cannot be verified by third parties, this promise must be self-enforceable.

The explicit bonus allows the agent to extract rent while the implicit salary promise does not. Thus, the principal can reduce the agent's rent by substituting explicit for implicit incentives. However, the self-enforcement requirement may impose an upper limit on the credible salary promise. In this case, the probability that the principal-agent relationship ends prematurely generates a trade-off between implicit and explicit incentives. Specifically, the bonus increases and the salary promise decreases with a higher probability of premature contract termination. At the same time, the agent's effort and, hence, productivity decreases.

We test the prediction of our model using personnel data from a large German insurance company. The dataset contains detailed information on individual revenues, compensation, and other characteristics for more than 300 employees over the course of five years. First, we estimate the expected survival time of an employee within the firm. Second, we proxy expected contracted duration by the mean expected survival time when estimating a simultaneous equations model. As predicted by our theoretical model, longer expected contract duration increases the fixed salary and productivity while decreasing variable pay. Third, we show that the productivity effect of expected contract duration is confined to the induced trade-off between fixed and variable pay. 
The standard, one-period principal-agent model is often considered to be the building block of incentive theory. ${ }^{1}$ Although, Foster and Rosenzweig (1994) and Lazear (2000) successfully test its implications within work environments that rather perfectly fit the model assumptions, ${ }^{2}$ it is fair to say that empirical evidence is still "tenuous." ${ }^{3}$ For instance, Jensen and Murphy (1990) find that executive contracts lack strong performance-pay incentives. More recently, Freeman and Kleiner (2005) show that, due to monitoring and transaction costs, a piece rate system may increase labor productivity but not profits. Moreover, the announcement of future time rates increases productivity by twice the percentage realized when introducing piece-rates. Finally, a series of very well-crafted studies by Prendergast (1999, 2000, 2002a, 2002b) concludes that incentive intensities do not decrease with more uncertainty as predicted by the standard model.

Explanations of these findings typically rely on additional assumptions regarding the contracting environment. For example, Jensen and Murphy (1990) suggest that political forces both in the public sector and inside the organizations place limits on incentives for CEOs. According to Prendergast (2002a), private information becomes more valuable - and, thus, the moral hazard problem more acute - if the environment becomes more risky. Prendergast (2002b) adds that favoritism of supervisors can lead to lower incentive-intensities in less risky environments.

More radical, experimental economics suggests that agents are intrinsically motivated or supply effort as part of a gift exchange. ${ }^{4}$ Bénabou and Tirole (2006) then show that, with stronger monetary incentives, the agent increasingly doubts that supplying effort constitutes a "good deed." Consequently, such extrinsic incentives crowd out her intrinsic motivation. Alternatively, according to Sliwka (2007), stronger monetary incentives convey that the principal becomes more pessimistic about the agents' acceptance of an effort norm. Thus, by introducing high-powered incentives the "con-

\footnotetext{
${ }^{1}$ See Lazear and Oyer (2007), for instance.

${ }^{2}$ Prendergast (1999).

${ }^{3}$ Prendergast (2002a).

${ }^{4}$ See e. g. Fehr et al. (2007) and Hannan et al. (2002) respectively.
} 
formists" in the labor force - i. e. individuals who only accept the norm if sufficiently many others do as well - are led to reduce their effort.

Compared to these studies, our approach is more traditional. We follow Baker et al. (1994) and Pearce and Stacchetti (1998) who already analyze the interplay between implicit and explicit incentives that arises with the availability of both objective and subjective performance signals in the context of a repeated game. These studies primarily focus on the distributional effects of distorted or biased signals on the agent's risk-premium. MacLeod and Malcomson (1989) and Levin's (2003) extend the results from repeated agency model distinguishing between common and private performance monitoring. With risk-neutral principal and agent, court-enforceable performance pay and self-enforcing income promises are shown to constitute perfect substitutes.

In contrast, we find that implicit salary promises always dominate if the agent is liquidity-constrained and not all promises are credible. Specifically, if credibility constrains the salary promise, the contract comprises additional explicit performance pay. In this case, the agent captures a rent and her effort is only second-best. Our model is very tractable and yields testable implications concerning the trade-offs between the two incentive devices and the determinants of effort. To our knowledge, so far only Hayes and Schaefer (2000) investigate implicit contracts empirically. They show that the unexplained variation in current CEO-compensation is positively correlated with future firm performance. ${ }^{5}$

The dataset we use contains employees who coordinate the sales force of a large and long-established German insurance company. Using actual personnel data, we observe individual productivities, salaries, variable pay, and many other characteristics of the employees' tasks, career status, and job environment. We track employees from January 2003 until December 2007. Thus, the dataset comprises 1123 employee-year observations for 317

\footnotetext{
${ }^{5}$ Else, the existing evidence is rather circumstantial: for instance, Rayton (2003) reports that, although contracts lack explicit incentives based on firm performance, rank-and-file employees' incomes exhibit considerable performance sensitivities.
} 
individuals. Since average employee tenure is longer than 10 years, this data appears particularly well-suited to study reputational contracting.

Eisner and Strotz (1961) already remark that insurance contracts are "sold rather than bought". Insurance companies should therefore be very experienced in designing incentive contracts. In fact, performance pay constitutes a significant cost factor in this industry: in 2004, for instance, German life insurers paid out $10.2 \%$ of their gross premium revenue as commissions to their sales organizations. ${ }^{6}$ However, empirical research is mostly confined to analyses of distribution channels. ${ }^{7}$ Recently, only Cummins and Doherty (2006) focus on contract design when discussing the New York Attorney General's 2005 investigation into the possible adverse effects of contingent commissions.

Our contribution is therefore threefold: first, we provide a theoretical variation to analyze the interplay of explicit and implicit incentives. Second, we can rather directly test this particular mechanism using personnel data. Third, focussing on rank-and-file employees of an insurance company, we also provide new insights into the "real-world" design of incentive contracts.

The study proceeds as follows. Section 2 develops the theoretic model. Section 3 introduces the dataset and contains the econometric investigation. Section 4 concludes.

${ }^{6} \mathrm{BaFin}$ (2005). For the American property and casualty market Cummins and Doherty (2006) report that commissions for personal lines (commercial lines) amount to $9.7 \%$ (11.4 $\%)$ of gross premiums written.

${ }^{7}$ See the survey by Regan and Tennyson (2000). 


\section{Theoretical analysis}

\subsection{The model structure}

We analyze a contracting problem between a risk-neutral principal and a risk-neutral agent in a stochastically repeated environment. However, the agent is liquidity-constrained. Hence, payments to the agent must always be non-negative. ${ }^{8}$ After each production period the agent leaves the firm for exogenous reasons and the game ends with probability $(1-p)$. Thus, the game is repeated next period with probability $p$. For parsimony, we assume that there is no discounting. Moreover, we restrict the analysis to simple contracts with no memory.

In any given production period the agent supplies productive effort $e \in$ $[0,1]$. This effort generates value $v(e)$ with $v^{\prime}(e)>0$ and $v^{\prime \prime}(e)<0$. The agent's effort can be thought of as an internal service. Hence, effort itself, $e$, and its contribution to firm value, $v(e)$, are non-verifiable by a third party. Consequently, they are not explicitly contractible. The agent's private costs of effort are given by $c(e)=e^{2}$ and her outside option is set equal to zero. To guarantee an interior solution for the firm's overall optimization problem, we impose the additional requirement that $v^{\prime}(1)<2 .^{9}$

The principal is assumed to observe the agent's effort $e .^{10}$ Moreover, there is a monitoring technology generating a verifiable binary signal $s$ with $s \in\{0,1\}$. For parsimony, we let $\operatorname{Pr}[s=1 \mid e]=e$ - hence, we measure effort in terms of the probability to observe the favorable signal. Due to the repeated nature of the game, the principal can use both implicit and explicit incentives in order to align incentives. Specifically, a contract is a triplet, $\mathcal{C}=\{b, w, E\}$, where $b$ denotes a bonus to be paid if the verifiable signal is

\footnotetext{
${ }^{8}$ If the agent were not liquidity constrained, he could simply buy the production possibility. It is well-known that a moral hazard problem does not arise in this case.

${ }^{9}$ The assumption guarantees that the first-best effort is smaller than 1 which we need in order to obtain an interior solution. Alternatively, the model can be generalized by introducing an increasing convex cost of effort function satisfying $\lim _{e \rightarrow 1} c(e)=+\infty$.

${ }^{10}$ Equivalently he can infer $e$ from $v(e)$.
} 
favorable, $s=1$. Further, $w$ denotes a salary that the principal promises to pay if he observes effort $e \geq E$.

The bonus part of the contract constitutes an explicit agreement that is court-enforceable. In contrast, the salary is an implicit agreement which must be self-enforcing. In other words, assuming the agent supplies effort $e \geq E$, it must be more advantageous for the principal to keep his promise and pay $w$ rather than to renege. In the case of reneging the principal looses his credibility. In all future periods, he can then only offer pure explicit contracts.

The timing of the game is as follows: first, the principal designs a contract and makes a take-or-leave-it offer to the agent. Second, the agent either rejects or accepts the offer. If the agent rejects, the game ends. Third, if the agent accepts the contract, she supplies effort. Next nature determines the realization of the monitoring signal $s$. Fourth, depending on the realization of this signal, the agent may receive a bonus. Also, contingent on his observation of the agent's effort, the principal either pays $w$ or reneges.

\subsection{The pure explicit contract}

In this subsection, we analyze the fallback contract where the principal solely relies on an explicit bonus to implement the agent's effort. Hence, both the salary promise $w$ and the threshold $E$ that would trigger the salary payment are set equal to zero. We apply backward induction.

With such a pure explicit contract, there is no decision in stage four. In stage three, given a bonus $b$ and initially assuming that the agent participates, she supplies the effort level $e^{b}$ defined by

$$
b=c^{\prime}\left(e^{b}\right)=2 e^{b} .
$$

Let $C^{X}(e)$ denote the principal's cost of inducing effort $e$ using explicit contracting only. It follows that 


$$
C^{X}(e)=2 e^{2} .
$$

The difference between the principal's cost of inducing effort and the agent's true effort costs measures the agent's rent, $R(e)$. Accounting for the agent's quadratic cost function her rent is

$$
R(e)=C^{X}(e)-c(e)=e^{2} .
$$

Since the rent is always non-negative, the agent's participation condition in stage two is always satisfied.

Further, this result illustrates that requiring non-negative payments to the agent is essential for the analysis. Otherwise a principal wishing to implement effort $e$ could demand an ex-ante fixed fee of $R(e)$ from the agent. The agent would only be allowed to participate in production upon paying this fee. In that case the principal could extract the entire rent from the agent and implement the first-best effort level.

Finally, in stage one the principal determines the optimal contract: he solves for the optimal effort $e^{X}$ (and, thus, for $b^{X}=c^{\prime}\left(e^{X}\right)$ ) by maximizing his expected profit

$$
\pi^{X}=\max _{e} v(e)-2 e^{2} .
$$

The value of $\pi^{X}$ then constitutes the principal's per-period fallback profit if he were to renege on the implicit contract and, thereby, loose his credibility.

\subsection{The general contract}

We proceed by analyzing the general contract that may include a salary promise to set additional implicit effort incentives. Again, we apply backward induction. 


\section{Stage four}

Suppose the agent has accepted a contract $\mathcal{C}=\{b, w, E\}$. In the final stage, the principal must determine whether to keep to his salary promise, $w$, or renege on his pledge. By reneging the principal saves on paying out $w$, but looses the agent's trust for all future periods. Suppose that, with trust, the principal obtains per-period expected profits $\pi^{I}$. Then, the principal looses $\left(\pi^{I}-\pi^{X}\right)$ in every future period by reneging on her promise.

Accounting for the probability $(1-p)$ that the game ends for exogenous reasons, the principal's promise to pay $w$ is credible only if

$$
\sum_{t=1}^{\infty} p^{t-1}\left(\pi^{I}-\pi^{X}\right)=\phi\left(\pi^{I}-\pi^{X}\right) \geq w,
$$

where $\phi=p /(1-p)$. In the remaining, $W=\phi\left(\pi^{I}-\pi^{X}\right)$ denotes the maximum credible salary promise.

\section{Stage three}

At stage three of the game, the agent must decide among three alternatives:

1. If $w$ is not credible, the agent will anticipate the principal's behavior and her expected income is equal to the expected bonus. As a result, she only supplies effort $e=e^{b}$ equating her marginal revenue to her marginal cost of effort.

2. If $w$ is credible and $E \leq e^{b}$, the agent's expected revenue function entails an upward step of value $w$ upon reaching some effort level $e \leq e^{b}$. Thus, the agent again supplies effort $e^{b}$ and takes the additional salary, $w$, as a windfall gain.

3. If $w$ is credible and $E>e^{b}$, the agent can gain the additional salary $w$ only if supplying an effort level $e>e^{b}$. Thus, there are two possible cases: 
(a) if

$$
w+E b-c(E) \geq e^{b} b-c\left(e^{b}\right)
$$

the agent supplies effort $e=E$.

(b) If (6) is not satisfied, the agent again chooses the effort level $e=e^{b}$ and foregoes the promised salary.

\section{Stage two}

A rational agent anticipates that she will always supply either $e=E$ or $e=e^{b}$. Due to (6), her rent is greater or equal to $R\left(e^{b}\right) \geq 0$. Thus, she always decides to participate in stage two.

\section{Stage one}

To solve the first stage of the game, we proceed as in the preceding section: first, we derive the principal's minimum cost function of inducing some effort level $e$ given the maximum credible salary $W$, hereafter $C^{I}(e, W)$. Next, we use $C^{I}(e, W)$ to solve for the optimal contract.

\section{The minimum cost function $C^{I}(e, W)$}

Suppose the principal wants to implement effort $e$. From the foregoing, we know there are two relevant cases. First, consider the case $e=e^{b}$. Anticipating the agent's response in stage three, the principal should obviously set $w=E=0$. Consequently, the contract is a pure explicit agreement and the principal's cost for implementing $e$ is $C^{X}(e)=2 e^{2}$.

Alternatively, suppose the principal sets $e=E>e^{b}$. For ease of notation, 
we eliminate $E$. The principal must then solve the design problem

$$
\begin{gathered}
C^{I}(e, W)=\min _{e^{b}, w, b} w+b e \quad \text { s.t. } \quad e>e^{b} \\
b=c^{\prime}\left(e^{b}\right) \\
w+c^{\prime}\left(e^{b}\right) e-c(e) \geq c^{\prime}\left(e^{b}\right) e^{b}-c\left(e^{b}\right) \\
w \leq W
\end{gathered}
$$

Equation (IC1) implicitly defines $e^{b}$. Condition (IC2) states that the agent would be better of by supplying $e$ rather than $e^{b}$. Finally, (CC) guarantees that the contract is credible.

First, consider situations where $W \geq c(e)$. In that case, the principal can set $w=c(e), b=0$, and $E=e$. He would then induce $\operatorname{costs} C^{I}(e, W)=$ $c(e)$. Clearly, the principal cannot do better without violating the agent's participation constraint. Since $b=0$ implies $e^{b}=0$, constraint (IC2) is binding in the optimization problem (I) above.

Next, consider the case $W<c(e)$. Suppose that (IC2) were not binding at the cost minimum. In this case, a marginal reduction in $b$ would reduce $e^{b}$, thereby decreasing the right hand side of (IC2) without violating any of the constraints. However a reduction in $b$ then also lowers the principal's cost. Hence, (IC2) must again be binding given a cost-minimizing contract.

Accounting for the quadratic cost function, substituting from (IC2) and solving therefore implies

$$
\begin{aligned}
w+2 e e^{b}-e^{2} & =\left(e^{b}\right)^{2} \\
& \Rightarrow w=\left(e-e^{b}\right)^{2} .
\end{aligned}
$$

Recalling that $e>e^{b}$, yields

$$
e^{b}=e-\sqrt{w}
$$

Consequently, to minimize costs the principal should set the bonus as low as possible while adjusting salary. For the case $W<c(e)$, it must therefore be 
true that $w=W$ implying $^{11}$

$$
C^{I}(e, W)=W+2 e(e-\sqrt{W}) .
$$

Rearranging terms, we can finally rewrite the principal's minimum cost function for $W<c(e)$ as

$$
C^{I}(e, W)=e^{2}+(e-\sqrt{W})^{2}
$$

Expression (10) helps to clarify the source of the cost saving potential associated with the salary promise as an additional implicit effort incentive. At one extreme with $W=0$, observe that $C^{I}(e, 0)=C^{X}(e)=2 e^{2}$. At the other extreme where $W \geq c(e)$, it follows that $C^{I}(e, W)=c(e)=e^{2}$. Then, consider intermediary values of $W$ with $0<W<c(e)$. Within this range, $C_{W}^{I}(e, W)=1-e / \sqrt{W}<0$ since $W<c(e)=e^{2}$.

Intuitively, a higher maximum credible salary $W$ allows the principal to increase his salary promise $w$ and to lower the explicit bonus $b$. The latter always reduces the agent's rent associated with the implied value of $e^{b}$. However, this potential to reduce costs is limited by the credibility constraint (CC). Consequently, $w=W$ in the cost minimum.

\section{Expected profit maximization}

In the foregoing, we considered $W$ to be exogenously given. In fact, it is endogenously determined by (5) which compares present value loss from cheating to the one time saving in salary. Thus the principal solves

$$
\begin{aligned}
\pi^{I}= & \max _{e, W} v(e)-C^{I}(e, W) \\
& \phi\left[v(e)-C^{I}(e, W)-\pi^{X}\right] \geq W
\end{aligned}
$$

Consider the case where the self-enforcement constraint (SC) is not binding. Accordingly, taking the derivative with respect to $W$ yields $C_{W}^{I}(e, W)=$

\footnotetext{
${ }^{11}$ Observe that $b=c^{\prime}\left(e^{b}\right)=2(e-\sqrt{W})$.
} 
0 which, from above, necessarily implies $W \geq c\left(e^{I}\right)$, where superscript "I" denote optimal values. From the foregoing, we know that with $W \geq c\left(e^{I}\right)$ the principal offers a pure implicit contract, i.e. a contract containing only a salary promise $w^{I}=c\left(e^{I}\right)$ and no explicit bonus, $b^{I}=0$. The optimal effort $e^{I}$ must then be first-best. Hence, $e^{I}=e^{*}$ where $e^{*}$ satisfies $v^{\prime}\left(e^{*}\right)=c^{\prime}\left(e^{*}\right)$.

However, if the maximum credible salary promise $W$ is smaller than $c\left(e^{*}\right)$, the self-enforcement constraint (SC) must be binding. In the remaining, we focus on this second case. It then follows that $C^{I}(e, W)$ is given by (10) above. Since $w=W$ we can further simplify the notation to obtain the Lagrangian

$$
L=v(e)-C^{I}(e, w)+\eta\left\{\phi\left[v(e)-C^{*}(e, w)-\pi^{X}\right]-w\right\} .
$$

The respective first-order conditions with respect to $e$ and $w$ yield:

$$
\begin{aligned}
{\left[v^{\prime}\left(e^{I}\right)-C_{e}^{I}\left(e^{I}, w^{I}\right)\right]\left[1+\eta^{I} \phi\right] } & =0 \\
-C_{w}^{I}\left(e^{I}, w^{I}\right)\left[1+\eta^{I} \phi\right]-\eta^{I} & =0 .
\end{aligned}
$$

The multiplier $\eta^{I}$ is non-negative such that $\left[1+\eta^{I} \phi\right]>0$. Given (10), condition (12) then immediately reveals that the optimal effort level is second-best. Specifically, $e^{I} \leq e^{*}$ with equality if, and only if, $\eta^{I}=0$.

\subsection{Properties of the optimal contract}

Given the case where the self-enforcement constraint (SC) is binding and using (10) from above, the solution $\left(e^{I}, w^{I}\right)$ is implicitly defined by the system of equations

$$
\begin{gathered}
v^{\prime}\left(e^{I}\right)-4 e^{I}-2 \sqrt{w^{I}}=0 \\
\phi\left[v\left(e^{I}\right)-w^{I}-2 e^{I}\left(e^{I}-\sqrt{w^{I}}\right)-\pi^{X}\right]-w^{I}=0
\end{gathered}
$$

Applying the implicit function theorem therefore yields:

$$
\left(\begin{array}{c}
\frac{\partial e^{I}}{\partial \phi} \\
\frac{\partial w^{I}}{\partial \phi}
\end{array}\right)=-\left(\begin{array}{cc}
v^{\prime \prime}\left(e^{I}\right)-4 & -1 / \sqrt{w^{I}} \\
0 & -\phi\left[1-e^{I} / \sqrt{w^{I}}\right]-1
\end{array}\right)^{-1}\left(\begin{array}{c}
0 \\
\frac{w^{I}}{\phi}
\end{array}\right)
$$


On first sight, the sign of the expression $-\phi\left[1-e^{I} / \sqrt{w^{I}}\right]-1$ appears unclear. However, it follows from (13) that

$$
-\phi C_{w}^{I}\left(e^{I}, w^{I}\right)=\frac{\eta^{I} \phi}{1+\eta^{I} \phi} \Longrightarrow-\phi\left[1-e^{I} / \sqrt{w^{I}}\right]-1=\frac{-1}{1+\eta^{I} \phi}<0
$$

since $\eta^{I} \geq 0$. Let $\Delta^{I}$ denote the determinant of the matrix in (15). Clearly, $\Delta^{I}$ must be positive. Thus, inverting this matrix and solving yields

$$
\begin{gathered}
\frac{\partial e^{I}}{\partial \phi}=\frac{1}{\Delta^{I}} \cdot \frac{w^{I}}{\phi} \frac{1}{\sqrt{w^{I}}}>0 \\
\frac{\partial w^{I}}{\partial \phi}=\frac{1}{\Delta^{I}} \cdot \frac{w^{I}}{\phi}\left(4-v^{\prime \prime}\left(e^{I}\right)\right)>0
\end{gathered}
$$

Denoting the expected bonus with $B^{I}=e^{I} b^{I}=2 e^{I}\left(e^{I}-\sqrt{w^{I}}\right)$, we can further determine the effect of a variation in $\phi$ as

$$
\begin{aligned}
\frac{\partial B^{I}}{\partial \phi} & =4 e^{I} \frac{\partial e^{I}}{\partial \phi}-2 \sqrt{w^{I}} \frac{\partial e^{I}}{\partial \phi}-2 e^{I} \frac{1}{0.5 \sqrt{w^{I}}} \frac{\partial w^{I}}{\partial \phi} \\
& =\frac{1}{\Delta^{I}} \cdot \frac{w^{I}}{\phi} \frac{1}{\sqrt{w^{I}}}\left[-2 \sqrt{w^{I}}+e^{I} v^{\prime \prime}\left(e^{I}\right)\right]<0
\end{aligned}
$$

upon substituting the respective partials, rearranging terms, and some simplification. Finally, since the expected bonus decreases while the probability of receiving the bonus increases, we can easily infer that $b^{I}$ must also be decreasing in $\phi$.

Altogether, we can characterize the optimal contract as follows:

Proposition 1 Suppose that the principal is constrained in making credible promises concerning future salaries. Then, the optimal contract $\mathcal{C}^{I}=$ $\left\{b^{I}, w^{I}, E^{I}\right\}$ is a function of the probability $p$ that the principal-agent relationship does not terminate prematurely. Specifically:

(a) An increase in $p$ increases the salary promise $w^{I}$ and the threshold effort level $E^{I}$ that triggers the payment of this salary.

(b) Since this threshold level $E^{I}$ is equal to the actual effort $e^{I}$ of the agent, productivity $v\left(e^{I}\right)$ also increases with higher probability $p$. 
(c) However, the explicit bonus $b^{I}$ that is paid out contingent on realizing a favorable monitoring signal as well as the expected bonus $B^{I}$ decrease with higher $p$.

The proposition yields a number of testable hypotheses with regard to the productivity effects of implicit salary promises and explicit bonus incentives as well as the trade-off between these two incentive devices. In the remaining, we use case study data to evaluate the theoretical analysis.

\section{Empirical analysis}

\subsection{The data}

To test the model we can draw on personnel data covering the German satellite offices of a large, globally operating insurance company. In 2003 there are 83 satellite offices (2004: 84, 2005: 80, 2006: 79 and 2007: 76). We can track employees from January 2003 until December 2007. The dataset comprises 1123 employee-year observations for 317 individuals.

Employment is highest (lowest) in 2003 (2007) providing 237 (209) annual records. Table 1 exhibits the numbers of employees leaving the firm in each year as well as during the complete observation period. These individuals are those who quit for reasons other than retirement. We also exclude employees who exit the satellite offices due to career moves within the firm.

\section{Insert Table 1 about here}

223 of those 237 individuals who are employed in the initial year 2003 do not retire and are not promoted during the observation period. Yet, 79 of these 223 employees quit the firm for personal reasons over this fiveyear period. For our econometric analysis we focus on this group of 223 individuals since retirement and promotion issues do not fit our theoretical 
analysis. Table 2 reports separate descriptive statistics for all employees and for our focus-group of 223 individuals. The respective entries do not indicate a selection problem.

Employees are between 24 and 64 years old and mostly male (92\%). The average age is 39 years. We construct a variable measuring the years of formal education ranging from 9 to 18 years. ${ }^{12}$ The mean of education is 11.8 years. Further, mean (maximum) company tenure is 12.7 (39) years. Using postal code information, we further measure the distance between the employee's home and her office. A substantial part of the employees works in the same town in which the satellite office is located (28.9\%). The mean distance (home_work) is $25 \mathrm{~km}$. Also, the mean distance between the company's head quarter and the satellite offices $\left(\right.$ dist_hq $_{-}$is $361.6 \mathrm{~km} .^{13}$

\section{Insert Table 2 about here}

We further use the German Statistical Office's dataset ${ }^{14}$ on the regional income tax distribution in 2001 to proxy local labor market and insurance demand conditions. The lowest annual tax per taxpayer (tax) is recorded in the district of Chemnitz in Saxony $(€ 2,847)$, the highest value is found in the district of Darmstadt in Hessia $(€ 8,770)$. Although, German unification already took place in 1990, unemployment ratios are still significantly higher and wages significantly lower in former East Germany. Thus, we introduce a dummy variable to identify whether the employee lives in former West Germany or Berlin (west_or_berlin).

\footnotetext{
${ }^{12}$ Specifically, a university degree is taken to require 18 years of studying (including schooling), a degree from a university of applied sciences ("Fachhochschule") 16 years, the university-preparatory school degree ("Abitur") 13 years, the subject-restricted university-preparatory school degree ("Fachochschulreife") 12 years, the degree of a commercial college ("Höhere Handelsschule") 11 years, the secondary modern school degree ("Realschule") 10 years, and the standard secondary school degree ("Volksschule" and "Hauptschule") 9 years.

${ }^{13}$ To protect the company's anonymity we do not report the maximum distance in this case.

${ }^{14}$ Federal Statistical Office (2008).
} 
The employees in our data set coordinate the insurer's exclusive agents in their regional areas and lines of business. Specifically, they do not sell insurance themselves. The company distinguishes between three business lines: life insurance, property and casualty insurance $\left(p_{-} c\right)$, and health insurance. In total, the sales agents controlled by our employees collect commissions worth $€ 654$ millions. The variable production used in the ensuing analysis sums all commissions that are paid out to an employee's subordinate sales personnel for new policies underwritten in a given year. It ranges from $€ 50,184$ to $€ 1,994,893$ with an average of $€ 605,077$. Mean production actually decreases from 2003 to 2004 and 2004 to 2005 and increases in the two remaining years.

Average employee earnings (total_income) are steadily increasing during our observation period, though at varying rates. ${ }^{15}$ Over all years it is equal to $€ 45,069$ on average with minimum and maximum incomes at $€$ 26,145 and $€ 73,755$. Roughly half (57\%) of the employees' income is fixed (fixed_salary). The remaining part (43\%) is performance pay (variable_pay) that is triggered by reaching production targets.

\subsection{The econometric strategy}

The econometric approach has to cope with a number of difficulties arising both from the nature of the data and the possible endogeneity of variables. In particular, the results summarized in Proposition 1 above are obtained from comparative static analysis and further insertions. Consequently, regressions to identify the determinants of fixed income, variable pay, and individual productivity are likely to be linked by their disturbances.

Thus, estimating the three functional relationships in Proposition 1 a) - c) necessitates the use of a simultaneous equations model $(S E M)$. Specifically,

\footnotetext{
${ }^{15}$ Throughout we adjust for inflation, of course.
} 
we choose the following basic $S E M$-structure:

$$
\begin{aligned}
\text { fixed_salary } & =\alpha_{1}+\beta_{1}^{S}(\text { survival })+\beta_{1}^{I}(\text { total_income })+X \gamma_{1}+\varepsilon_{1} \\
\text { variable_pay } & =\alpha_{2}+\beta_{2}^{S}(\text { survival })+\beta_{2}^{I}(\text { total_income })+X \gamma_{2}+\varepsilon_{2} \\
\text { production } & =\alpha_{3}+\beta_{3}^{S}(\text { survival })+Z \gamma_{3}+\varepsilon_{3} \\
\text { total_income } & =\text { fixed_salary }+ \text { variable_pay }
\end{aligned}
$$

where survival constitutes our proxy of the expected duration $\phi$ of the contract. We provide a detailed description of how we obtained this proxy below. Clearly, $\varepsilon_{i}, i=1,2,3$, denotes the respective error term. Finally, $X$ and $Z$ denote matrices of independent variables to control for other individual, jobspecific, and market effects on income and productivity.

To estimate our model we must identify variables that on the one hand effect productivity and on the other hand do not impact an employee's compensation and vice versa. Regarding the former, we clearly expect that commissions and, hence, our productivity measure differs between the lines of business (life, $p_{-} c$, health). However, job-competition within the firm precludes that such differences affect income opportunities.

In contrast, distance from firm's headquarters (dist_hq) should exhibit only income effects. Specifically, a possible lack of promotion opportunities within the firm's main administration should be compensated. Also, gender effects on pay are well-documented. Thus, we include male only in the equations for fixed and variable pay. We can then test whether these two sets of variables - i. e. life, $p_{-} c$, and health vis-à-vis dist_hq and male - are actually exogenous.

While the first three lines in (20) correspond to parts a), b), and c) of Proposition 1, the last line merely reflects the pay accounting identity. Note that we use the same set of explanatory variables in both income equations. Hence, we could have eliminated this identity thereby reducing both the number of equations and the number of endogenous variables. However, estimating the complete structure (20) yields more easily interpretable results. ${ }^{16}$ Finally, accounting for between-equation correlation of the error

\footnotetext{
${ }^{16}$ In this respect note that, according to Zellner and Theil (1962, p. 68) and Greene
} 
terms, we estimate (20) using Three Stage Least Squares (3SLS).

\subsection{Expected contract duration}

From our theoretical model the expected contract duration $\phi$ (that is computed using the exogenous probability $p$ of premature contract termination) determines the optimal balance between implicit and explicit incentives. Clearly, our model assumes that the parties have rational expectations concerning this variable. Maintaining this assumption, we therefore use the information on quits to obtain a proxy of $\phi$.

Generally, we cannot integrate duration estimates into our simultaneous equations model (20) above. Instead we must obtain an independent estimate for the group of 223 employees who were employed in 2003 already and are not retired or promoted during the observation period. ${ }^{17}$ In a first step, Figure 1 then displays non-parametric estimates of the hazard and survival functions. They are clearly non-monotonic. For this case, Kalbfleisch and Prentice (1980) suggest to fit either a log-normal or a log-logistic duration model.

\section{Insert Figure 1 about here}

We use only two individual-specific covariates: the distance between the employee's home and her office (home_work) and the employee's corporate tenure in 2003 as percent of her potential tenure years. The latter is calculated as tenure divided by age minus education. This transformation reflects that - in contrast to productivity studies where "raw" tenure is often used to capture experience effects - our approach requires to identify a predictor for the individual's future quit behavior. ${ }^{18}$

Goodness-of-fit can be assessed by calculating the Akaike Information

(2003, p. 390), such identitities do not affect the identification problem.

${ }^{17}$ See e. g. Theodossiou and White (1998) for a similar approach.

${ }^{18}$ Also, the inclusion of other individual charcteristics as explanatory variables does not improve the overall quality of the estimate. 
Criterion $(A I C)$. This measure selects the model that explains the data best with a minimum of free parameters. Given our application, the value of the $A I C$-test for the log-normal model estimate is 236.37 compared to 239.10 for the log-logistic model. Thus, we proceed by using the log-normal estimate. ${ }^{19}$ Table 3 reports the respective results in the so-called "accelerated failure time form". Hence, positive coefficients imply a deceleration of time. ${ }^{20}$ Note that the joint restrictions are significant at the $1 \%$-level.

Insert Table 3 and Figure 2 about here

Figure 2 depicts the corresponding hazard function. The scaling parameter - denoted $\sigma$ in Table 3 - determines the skewness of this function. It is highly significant; the respective $z$-statistic (not reported) is equal to 3.53 . For our subsequent analyses, we then calculate the variable survival as the median predicted survival time for each individual. It serves as a proxy for the expected contract duration.

\subsection{Productivity and income structure}

Tables 4.a and $\mathrm{b}$ report the final and first stage estimations of the system (20) above. Recall that our survival time estimate focuses on the year 2003. Thus, the first sets of three equations in these tables uses only the income and productivity data for 2003. However, we also use the 2003 survival estimates to calculate the predicted mean survival times for the four subsequent years $2004-2007 .{ }^{21}$ The second set of equations Tables $4 . \mathrm{a}$ and $\mathrm{b}$ thus draws on

\footnotetext{
${ }^{19}$ However, we also fit a number of other duration models to the data. Yet, the Akaike Information Criterion (AIC) still prefers the log-normal duation model: the AIC of the Weibull model is 240.34, 238.37 for the exponential and 237.97 for the Gompertz models. The log-normal duration model also has the highest log-likelihood. We further use the semi-parametric Cox Proportional Hazard model that does not require specific distributional assumptions. The respective estimates are very similar to those reported in Table 3.

${ }^{20}$ See Martinussen and Scheike (2006).

${ }^{21}$ Using a probit model on the full sample of employees, we have checked that these expected survival times constitute very good predictors of the actual quit behavior.
} 
the full set of 878 observations for the group of 223 individuals who are not retired or promoted during the observation period. ${ }^{22}$

Insert Tables 4.a and 4.b about here

Overall significance is very solid for both estimates: lacking the possibility to report $R^{2}$-values for the final stage, the corresponding $\chi^{2}$-tests reject the hypothesis that all coefficients are equal zero. Also, the respective $F$-tests do not indicate a weak instrument problem. We follow Wooldridge (2002) in using a version of the Hausman-test to investigate whether the overidentification restrictions are valid. For one additional instrument the critical value of the over-identification test is 2.70 . Hence, we cannot reject the nullhypothesis that excluded variables are exogenous for any of our equations.

Focussing on the key variable survival, the symmetry of the coefficients for fixed salaries and variable pay in the final stage directly follows from explicitly including the total_income identity. However, note that, even given this constraint, the final stage regression could still yield three different scenarios: survival could in principle either increase variable pay at the expense of fixed_salary, decrease variable pay while increasing fixed_salary, or show no effect on the income structure at all. Only the second of these scenarios is consistent with our theory, though.

The results reported in Table 4.a then strongly support all three parts of the Proposition 1. Moreover, it does not matter whether we limit the estimation to the year 2003 or consider the full observation period 2003 2007. Although the results are somewhat stronger using the larger sample, ${ }^{23}$ both approaches confirm that longer expected durations of contracts increase fixed salaries at the expense of reducing variable pay. At the same time,

\footnotetext{
${ }^{22}$ Thus, there are 223 individuals in 2003 of which $190(167,154,144)$ remain employed in the same function in 2004 (2005, 2006, 2007).

${ }^{23}$ Apart from the statistical effects of increasing the number of observations, an income promise which in theory would be realized "in the next period" can in practise well be delivered over a number of subsequent years.
} 
individual productivity increases with longer expected contract duration.

Insert Table 5 about here

Using an $S E M$-approach further allows for an interesting experiment: with the same first-stage regression reported in Table 4.b already, Table 5 contains the final stage estimates of an alternative system of equations obtained by replacing survival by variable_pay and fixed_salary as determinants of productivity. Specifically, we now estimate the system

$$
\begin{aligned}
\text { fixed_salary } & =\alpha_{1}+\beta_{1}^{S}(\text { survival })+\beta_{1}^{I}(\text { total_income })+X \gamma_{1}+\varepsilon_{1} \\
\text { variable_pay } & =\alpha_{2}+\beta_{2}^{S}(\text { survival })+\beta_{2}^{I}(\text { total_income })+X \gamma_{2}+\varepsilon_{2} \\
\text { production } & =\alpha_{3}+\beta_{3}^{F}(\text { fixed_salary })+\beta_{3}^{V}(\text { variable_pay })+Z \gamma_{3}+\varepsilon_{3} \\
\text { total_income } & =\text { fixed_salary }+ \text { variable_pay }
\end{aligned}
$$

Recall that the system (20) yields a coefficient-value of 906.48 for survival (in the sixth column of Table 4.a). The respective standard error is 329.73. According to system (21), the marginal effect of survival on production can be calculated as:

$$
\begin{aligned}
\beta_{3}^{F} \beta_{1}^{S}+\beta_{3}^{V} \beta_{2}^{S} & =-15.43 \times 20.55+25.77 \times 47.24 \\
& =904.93
\end{aligned}
$$

Hence, using a standard $t$-test, the hypothesis that $\beta_{3}^{S}$ as derived from (20) is significantly different from $\beta_{3}^{F} \beta_{1}^{S}+\beta_{3}^{V} \beta_{2}^{S}$ obtained when estimating (21) must be rejected. In other words, the importance of survival to explain production appears to be entirely captured by effect of survival on the contractual pay scheme.

Finally, we regress survival on the residuals of the production-equation obtained when estimating system (21). The coefficient value is -1.33 with standard error 294. The respective $t$-statistic is equal to zero. Hence, the income structure rather appears to reflect expectations of future contractual compliance than effects that stem from current productivity. 


\subsection{Robustness of results}

The final stage estimates in Tables 4.a and 5 are derived using the Three Stage Least Squares (3SLS) method. This model uses the information contained in the covariance matrix via Generalized Least Squares $(G L S)$ estimation. Thus, 3SLS incorporates all information contained in the system of equations to estimate all parameters in each individual equation. In contrast, Two Stage Least Squares (2SLS) only draws on the information in the specific individual equation to estimate the parameters from the corresponding equation. While $3 S L S$ is therefore more efficient, it bears the risk that a specification error in one equation will be transmitted to all other equations. Consequently, we also use 2SLS to estimate the models above. Compared with the results in Tables 4.a. and 5, the respective differences are minimal, however.

Since we know the number of sales agents controlled by each of the managers in our data set, we can also calculate management performance as production per agent. Obviously, using this variable to replace production as a productivity measure in (20), the coefficient values for survival change. Yet, there is no difference in their signs and significance levels. Further, we estimate model versions in which survival in year $t$ is taken to affect fixed_salary in year $t+1$. Clearly, the respective coefficients in the two income equations then cease to be mirror-images of each other. However, signs and significance levels are again not affected.

Finally, we can improve the overall explanatory power of our model by distinguishing different sets of explanatory variables for fixed_salary and variable_pay. Yet, in this case the equality of coefficients on survival between our two model versions (20) and (21) above cannot be checked as easily. To save space, we therefore decide not report any of the above extensions and variations of our basic model. However, they are available upon request. 


\section{Conclusions}

We derive the optimal contract between a principal and a liquidity-constrained agent in a stochastically repeated environment characterized by moral hazard. The contract comprises two parts; a court-enforceable explicit bonus rule based on a verifiable signal and an implicit salary promise conditioned on the observable, but not verifiable agent's effort. Hence, the latter promise must be self-enforcing. We find that the agent's rent increases with bonus pay. Thus, the principal implements the maximum credible salary promise. We then show that the bonus increases while the salary promise and the agent's effort decrease with a higher probability of premature contract termination.

We subject the mechanism of our model to an econometric investigation that draws on personnel data of a large German insurance company. Using a hazard rate model, we first obtain estimates of the employees' expected survival within the firm based on individual characteristics. These estimates enter into a simultaneous equations system that, under the assumptions of our model, identifies the determinants of fixed salary, variable pay, and productivity. The results strongly support our theoretical predictions: the interplay between fixed and variable pay is determined by the expected contract duration. Moreover, this incentive mechanism drives productivity. Thus, employers capture efficiency gains by replacing bonuses with salary promises for employees who are characterized by higher probabilities to stay with the firm.

The results of our analysis can also be interpreted in light of the ongoing discussion of environmental risk and contract design. Intuitively, a higher probability of premature contract termination reflects more uncertainty in the employment relationship. According to our findings, we should observe a reduction in salaries and effort together with an increase in bonus pay; yet without contradiction to standard incentive theory. 


\section{References}

BaFin (2005). Statistik der BaFin - Erstversicherungsunternehmen '04 (Lebensversicherung), Table 140, Sections 10 a and b, Bonn, Germany:Bundesanstalt für Finanzdienstleistungsaufsicht - BaFin. Accessible via: www. bafin.de.

Baker, George P., Robert Gibbons, and Kevin J. Murphy (1994). Subjective Performance Measures in Optimal Incentive Contracts. Quarterly Journal of Economics, vol. 109, 1125-1156.

Bénabou, Roland and Jean Tirole (2006). Incentives and Prosocial Behavior. American Economic Review, vol. 96, 1652-1678.

Cummins, David and Neil A. Doherty (2006). The Economics of Insurance Intermediaries. Journal of Risk and Insurance, vol. 73, 359-396.

Eisner, Robert and Robert H. Strotz (1961). Flight Insurance and the Theory of Choice. Journal of Political Economy, vol. 69, 355-368.

Federal Statistical Office (2008). Regional Database Germany, Statistics 73111, Table 368-01-3, Year 2001, Düsseldorf, Germany: Federal Statistical Office and the Statistical Offices of the Länder. Accessible via www.regionalstatistik.de.

Fehr, Ernst, Alexander Klein and Klaus M. Schmidt (2007). Fairness and Contract Design. Econometrica, vol. 75, 121-154.

Foster, Andrew D. and Mark R. Rosenzweig (1994). A Test for Moral Hazard in the Labor Market: Contractual Arrangements, Effort, and Health. Review of Economics and Statistics, vol. 76, 213-27.

Freeman, Richard B. and Morris M. Kleiner (2005). The Last American Shoe 
Manufacturers: Changing the Method of Pay to Survive Foreign Competition. Industrial Relations, vol. 44, 307-330.

Greene, William H. (2003). Econometric Analysis, 5th Edition, Upper Saddle River, N. J.: Prentice Hall.

Hayes, Rachel M. and Scott Schaefer (2000). Implicit Contracts and the Explanatory Power of Top Executive Compensation for Future Performance. RAND Journal of Economics, vol. 31, 273-293.

Hannan, R. Lynn, John H. Kagel and Donald V. Moser (2002). Partial Gift Exchange in an Experimental Labor Market: Impact of Subject Population Differences, Productivity Differences, and Effort Requests on Behavior. Journal of Labor Economics, vol. 20, 923-951.

Jensen, Michael C. and Kevin J. Murphy (1990). Performance Pay and TopManagement Incentives. Journal of Political Economy, vol. 98, 225-264.

Kalbfleisch, John D. and Ross L. Prentice (1980). The Statistical Analysis of Failure Time Data, New York: Wiley \& Sons.

Lazear, Edward P. (2000). Performance Pay and Productivity. American Economic Review, vol. 90, 1346-1361.

Lazear, Edward P. and Paul Oyer (2007). Personnel Economics. NBER Working Papers 13480.

Levin, Jonathan (2003). Relational Incentive Contracts. American Economic Review, vol. 93, 835-857.

MacLeod, Bentley and James Malcomson (1989). Implicit Contracts, Incentive Compatibility, and Involuntary Unemployment. Econometrica, vol. 57, 447-480. 
Martinussen, Torben and Thomas H. Scheike (2006). Dynamic Regression Models for Survival Data, New York: Springer.

Pearce, David G. and Ennio Stacchetti (1998). The Interaction of Implicit and Explicit Contracts in Repeated Agency. Games and Economic Behavior, vol. 23, 75-96.

Prendergast, Canice (1999). The Provision of Incentives in Firms. Journal of Economic Literature, vol. 37, 7-63.

Prendergast, Canice (2000). What Trade-Off of Risk and Incentives? American Economic Review, vol. 90, 421-425.

Prendergast, Canice (2002a). The Tenuous Trade-Off between Risk and Incentives. Journal of Political Economy, vol. 110, 1071-1102.

Prendergast, Canice (2002b). Uncertainty and Incentives. Journal of Labor Economics, vol. 20, 115-137.

Rayton, Bruce A. (2003). The Residual Claim of Rank and File Employees. Journal of Corporate Finance, vol. 9, 129-148.

Regan, Laureen and Sharon Tennyson (2000). Insurance Distribution Systems. In: George Dionne (ed.), Handbook of Insurance, Boston, Dodrecht, and London: Kluwer, 709-748.

Sliwka, Dirk (2007). Trust as a Signal of a Social Norm and the Hidden Costs of Incentive Schemes. American Economic Review, vol. 97, 999-1012.

Theodossiou, Ioannis and Mark J. White (1998). Does Tenure Affect Earnings? Journal of Economic Studies, vol. 25, 328-343.

Wooldridge, Jeffrey M. (2002). Econometric Analysis of Cross Section and Panel Data, Cambridge: MIT Press. 
Zellner, Arnold and Henri Theil (1962). Three-Stage Least Squares: Simultaneous Estimation of Simultaneous Equations. Econometrica, vol. 30, 54-78. 
Figure 1: Non-Parametric Duration Estimates
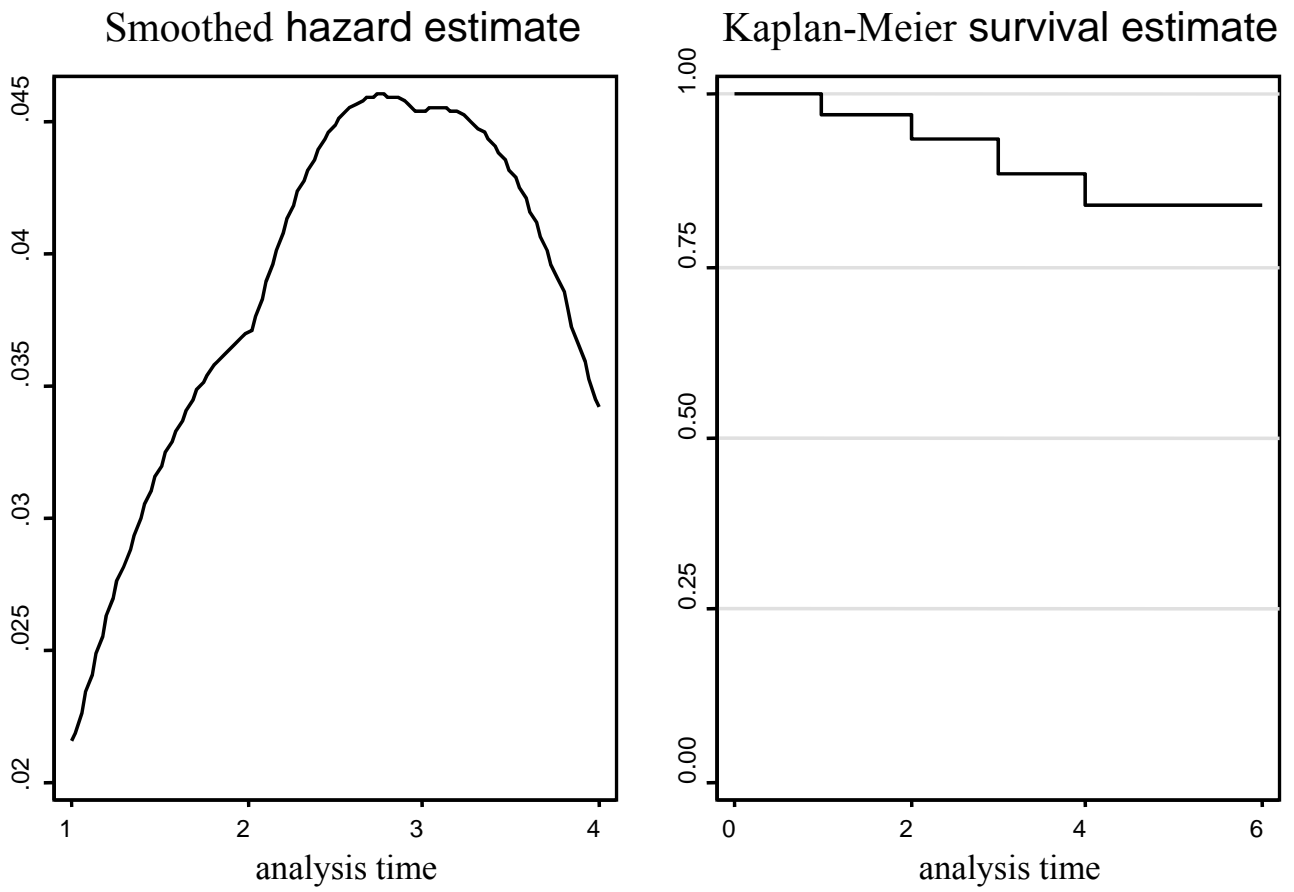

Figure 2: Hazard Function Estimates (Log-Normal Regression)

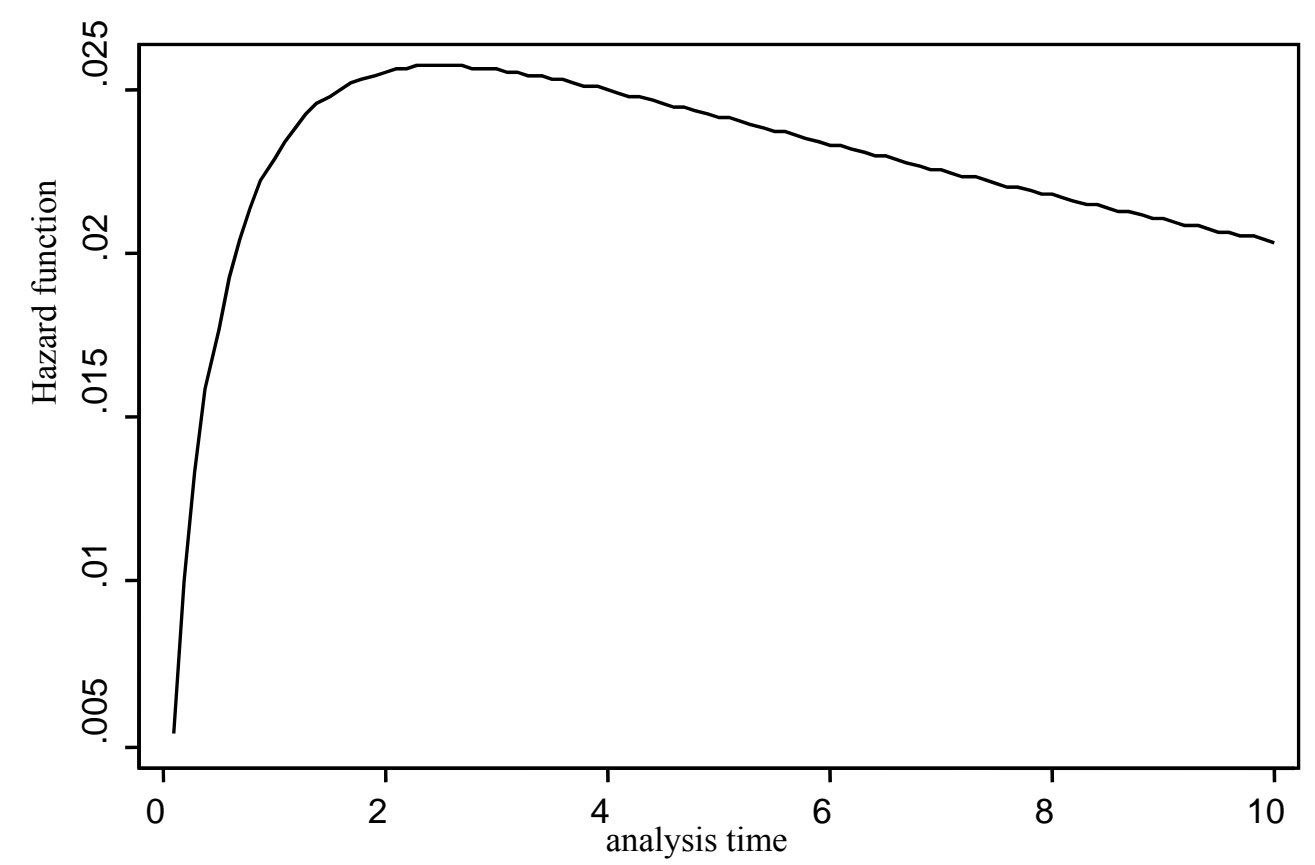


Table 1: Employees leaving the company

\begin{tabular}{lccc}
\hline Year & $\begin{array}{c}\text { Employees } \\
\text { in this year }\end{array}$ & $\begin{array}{c}\text { Employees } \\
\text { leaving in } \\
\text { this year }\end{array}$ & $\begin{array}{c}\text { Employees leaving until 2007 } \\
\text { (excluding retirees) }\end{array}$ \\
\hline 2003 & 237 & 8 & 31 \\
2004 & 234 & 12 & 28 \\
2005 & 229 & 13 & 19 \\
2006 & 214 & 15 & 11 \\
2007 & 209 & - & - \\
\hline
\end{tabular}




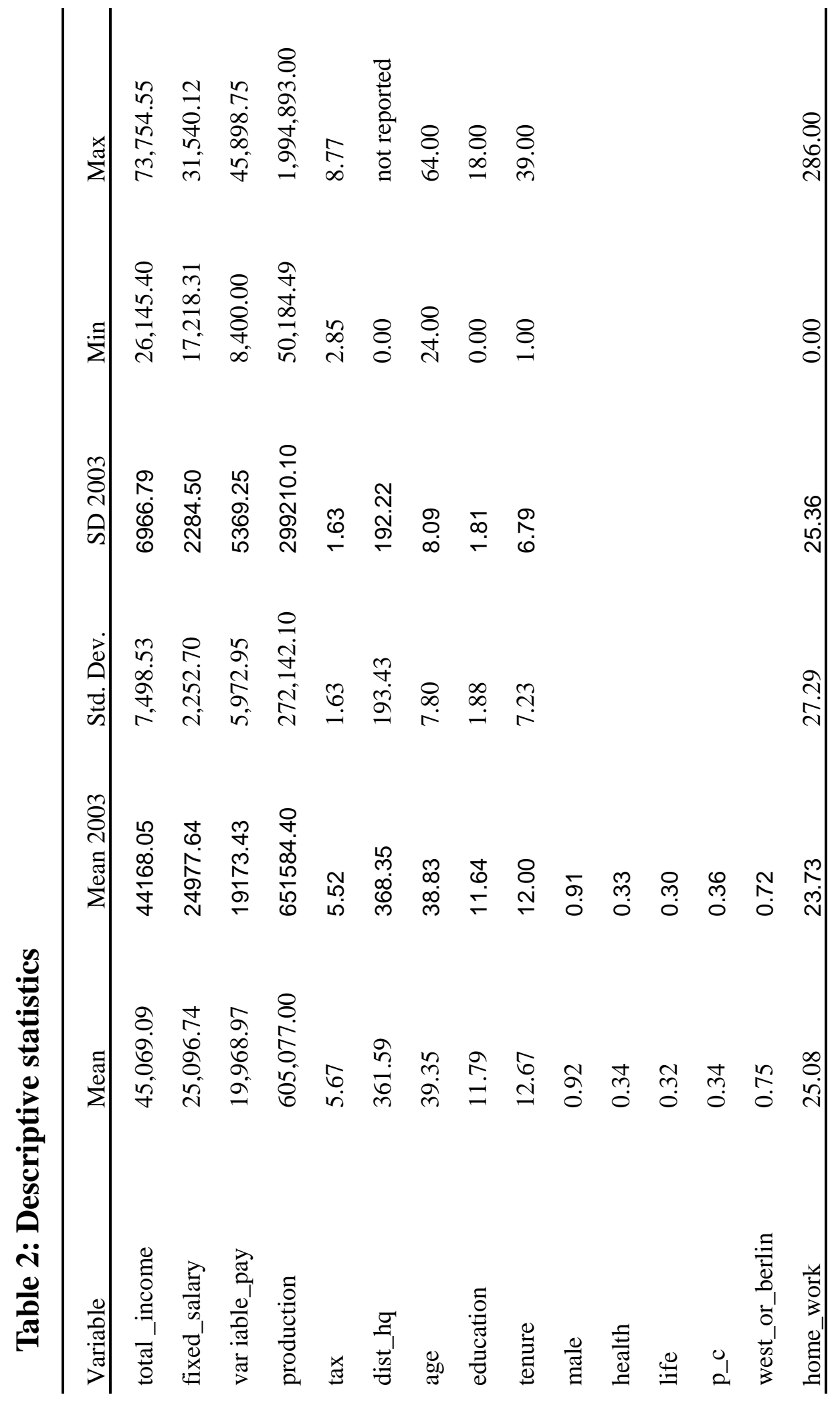


Table 3: Survival Time Estimate Log-Normal Model (Accelerated Failure-Time Form)

\begin{tabular}{|c|c|}
\hline & survival time \\
\hline tenure as percent of & 2.044 \\
\hline tenure potential & $(0.896)^{* *}$ \\
\hline \multirow[t]{2}{*}{ home_work } & -0.012 \\
\hline & $(0.007)^{*}$ \\
\hline \multirow[t]{2}{*}{ constant } & 3.099 \\
\hline & $(0.511)^{* * *}$ \\
\hline \multirow[t]{2}{*}{$\ln (\sigma)$} & 0.553 \\
\hline & $(0.157)^{* * *}$ \\
\hline observations & 223 \\
\hline LR Chi2 & 10.52 \\
\hline $\mathrm{p}$-value & 0.005 \\
\hline time at risk & 1226.000 \\
\hline $\mathrm{N}$ failures & 31 \\
\hline Note: $\ln (\sigma) \rightarrow \sigma=1.739$ & \\
\hline
\end{tabular}

Standard errors in parentheses; *significant at $10 \% ; * *$ significant at $5 \%$; $* * *$ significant at $1 \%$. 


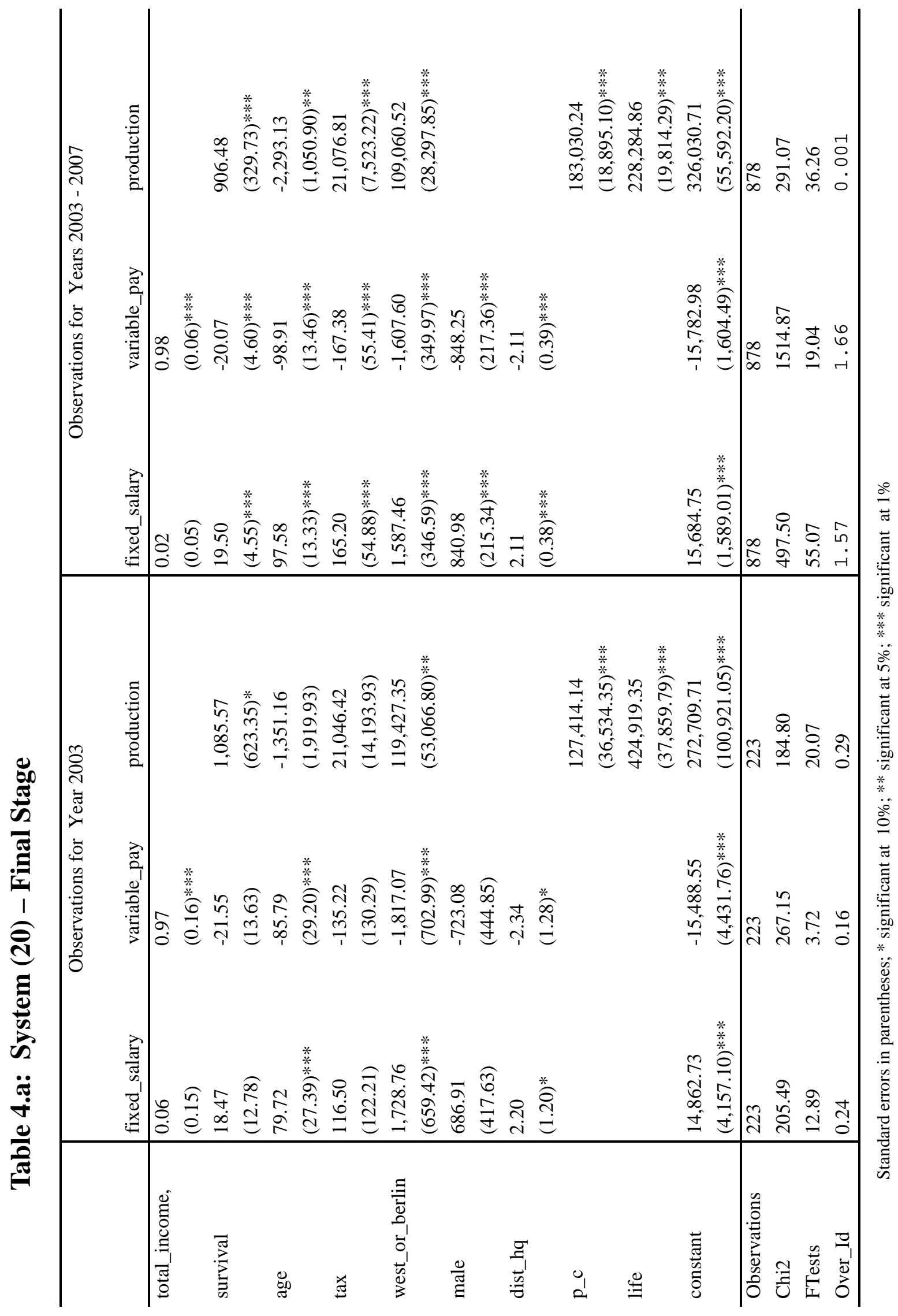




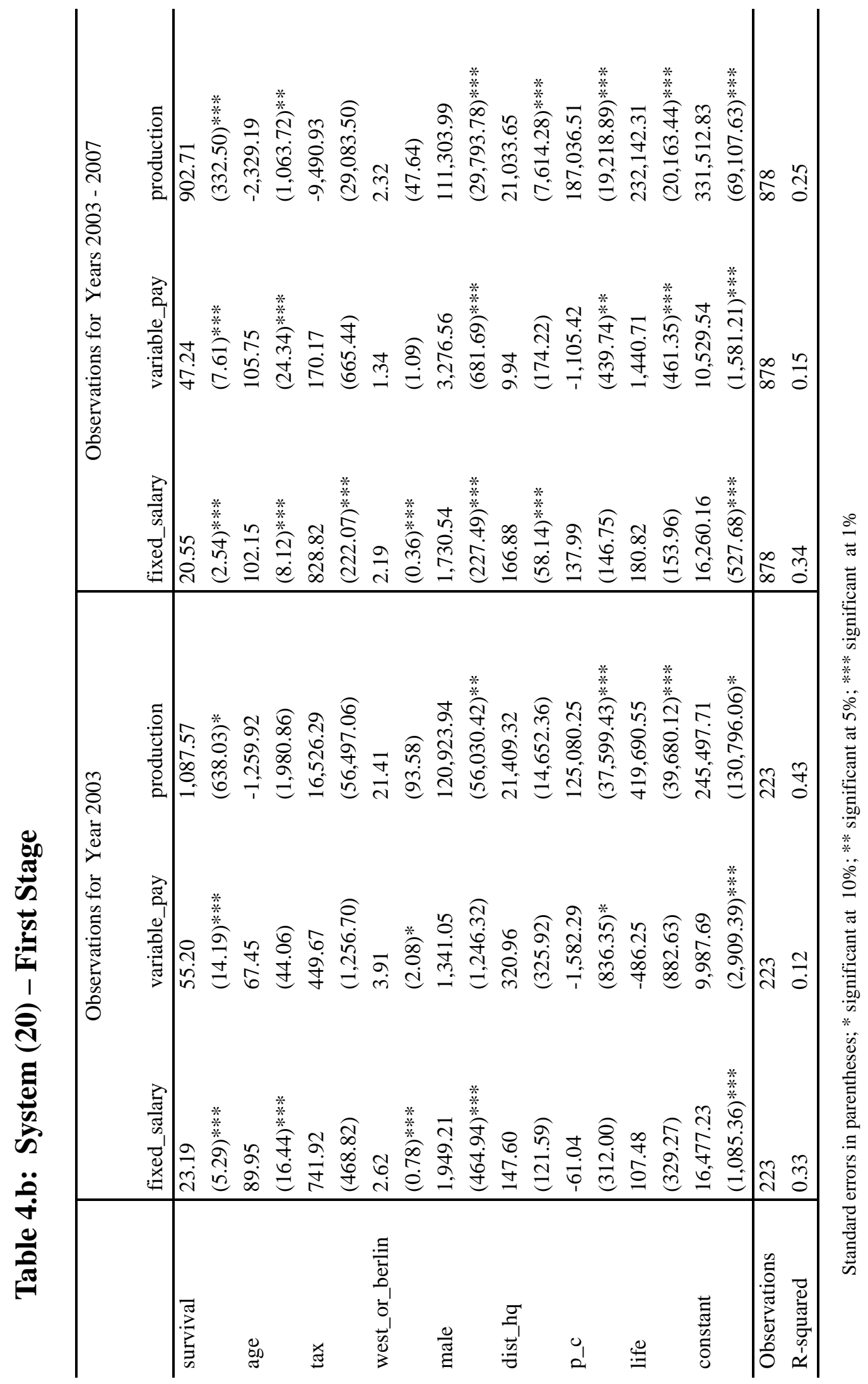




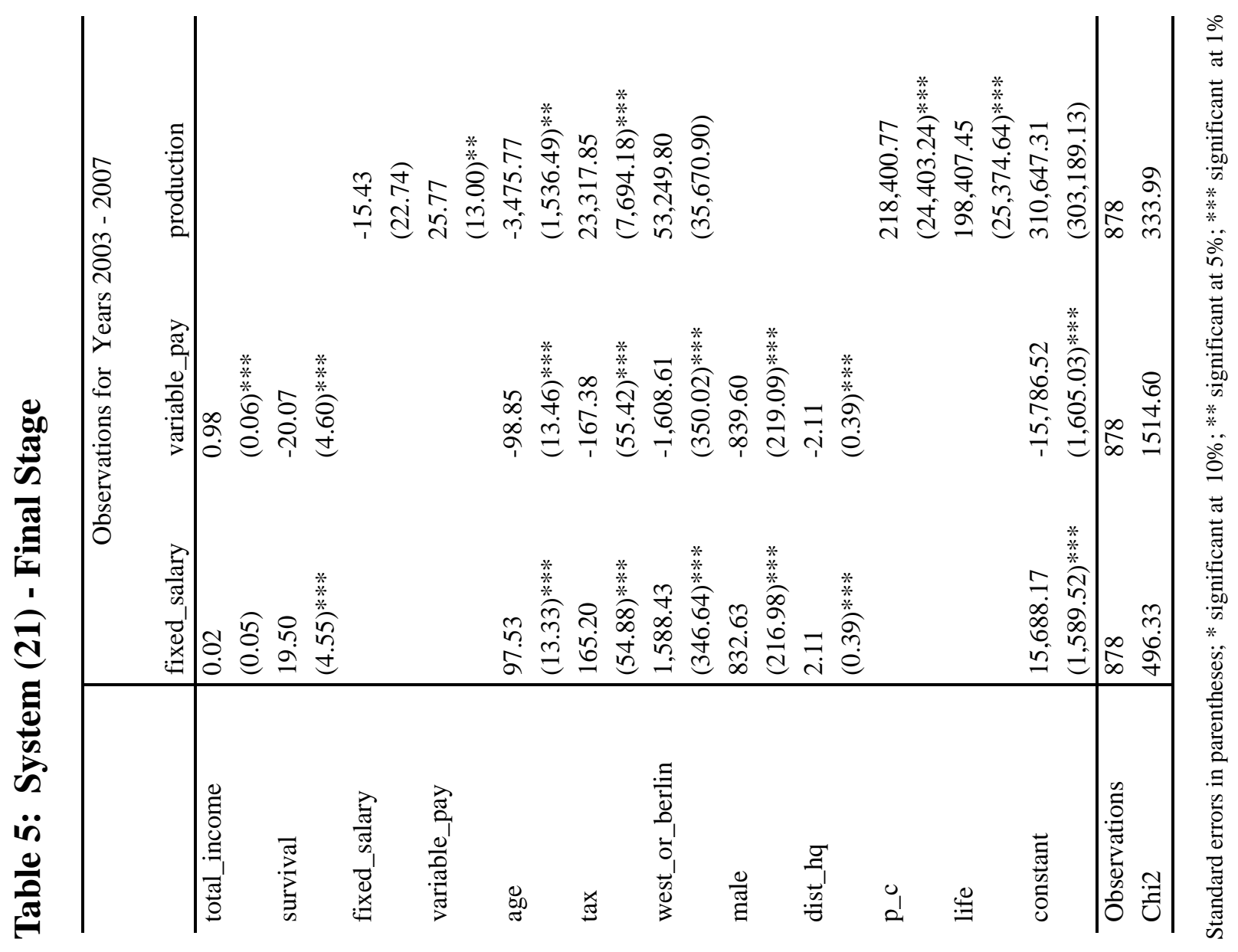




\section{CESifo Working Paper Series}

for full list see www.cesifo-group.org/wp

(address: Poschingerstr. 5, 81679 Munich, Germany, office@cesifo.de)

2581 António Afonso and Christophe Rault, Bootstrap Panel Granger-Causality between Government Budget and External Deficits for the EU, March 2009

2582 Bernd Süssmuth, Malte Heyne and Wolfgang Maennig, Induced Civic Pride and Integration, March 2009

2583 Martin Peitz and Markus Reisinger, Indirect Taxation in Vertical Oligopoly, March 2009

2584 Petra M. Geraats, Trends in Monetary Policy Transparency, March 2009

2585 Johannes Abeler, Armin Falk, Lorenz Götte and David Huffman, Reference Points and Effort Provision, March 2009

2586 Wolfram F. Richter, Taxing Education in Ramsey’s Tradition, March 2009

2587 Yin-Wong Cheung, Menzie D. Chinn and Eiji Fujii, China's Current Account and Exchange Rate, March 2009

2588 Alexander Haupt and Silke Uebelmesser, Voting on Labour-Market Integration and Education Policy when Citizens Differ in Mobility and Ability, March 2009

2589 Hans Jarle Kind, Marko Koethenbuerger and Guttorm Schjelderup, Should UtilityReducing Media Advertising be Taxed?, March 2009

2590 Alessandro Cigno, How to Avoid a Pension Crisis: A Question of Intelligent System Design, March 2009

2591 Helmut Lütkepohl and Fang Xu, The Role of the Log Transformation in Forecasting Economic Variables, March 2009

2592 Rainald Borck, Hyun-Ju Koh and Michael Pflüger, Inefficient Lock-in and Subsidy Competition, March 2009

2593 Paolo M. Panteghini, On the Equivalence between Labor and Consumption Taxation, March 2009

2594 Bruno S. Frey, Economists in the PITS?, March 2009

2595 Natalie Chen and Dennis Novy, International Trade Integration: A Disaggregated Approach, March 2009

2596 Frédérique Bec and Christian Gollier, Term Structure and Cyclicity of Value-at-Risk: Consequences for the Solvency Capital Requirement, March 2009 
2597 Carsten Eckel, International Trade and Retailing, March 2009

2598 Gianni De Nicolò and Iryna Ivaschenko, Global Liquidity, Risk Premiums and Growth Opportunities, March 2009

2599 Jay Pil Choi and Heiko Gerlach, International Antitrust Enforcement and Multi-Market Contact, March 2009

2600 Massimo Bordignon and Guido Tabellini, Moderating Political Extremism: Single Round vs Runoff Elections under Plurality Rule, April 2009

2601 Ana B. Ania and Andreas Wagener, The Open Method of Coordination (OMC) as an Evolutionary Learning Process, April 2009

2602 Simon Gächter, Daniele Nosenzo, Elke Renner and Martin Sefton, Sequential versus Simultaneous Contributions to Public Goods: Experimental Evidence, April 2009

2603 Philippe Jehiel and Andrew Lilico, Smoking Today and Stopping Tomorrow: A Limited Foresight Perspective, April 2009

2604 Andreas Knabe, Steffen Rätzel, Ronnie Schöb and Joachim Weimann, Dissatisfied with Life, but Having a Good Day: Time-Use and Well-Being of the Unemployed, April 2009

2605 David Bartolini and Raffaella Santolini, Fiscal Rules and the Opportunistic Behaviour of the Incumbent Politician: Evidence from Italian Municipalities, April 2009

2606 Erkki Koskela and Jan König, Can Profit Sharing Lower Flexible Outsourcing? A Note, April 2009

2607 Michel Beine, Frédéric Docquier and Çağlar Özden, Diasporas, April 2009

2608 Gerd Ronning and Hans Schneeweiss, Panel Regression with Random Noise, April 2009

2609 Adam S. Booij, Bernard M.S. van Praag and Gijs van de Kuilen, A Parametric Analysis of Prospect Theory's Functionals for the General Population, April 2009

2610 Jeffrey R. Brown, Julia Lynn Coronado and Don Fullerton, Is Social Security Part of the Social Safety Net?, April 2009

2611 Ali Bayar and Bram Smeets, Economic, Political and Institutional Determinants of Budget Deficits in the European Union, April 2009

2612 Balázs Égert, The Impact of Monetary and Commodity Fundamentals, Macro News and Central Bank Communication on the Exchange Rate: Evidence from South Africa, April 2009

2613 Michael Melvin, Christian Saborowski, Michael Sager and Mark P. Taylor, Bank of England Interest Rate Announcements and the Foreign Exchange Market, April 2009 
2614 Marie-Louise Leroux, Pierre Pestieau and Gregory Ponthiere, Should we Subsidize Longevity?, April 2009

2615 Ronald MacDonald, Lukas Menkhoff and Rafael R. Rebitzky, Exchange Rate Forecasters' Performance: Evidence of Skill?, April 2009

2616 Frederick van der Ploeg and Steven Poelhekke, The Volatility Curse: Revisiting the Paradox of Plenty, April 2009

2617 Axel Dreher, Peter Nunnenkamp, Hannes Öhler and Johannes Weisser, Acting Autonomously or Mimicking the State and Peers? A Panel Tobit Analysis of Financial Dependence and Aid Allocation by Swiss NGOs, April 2009

2618 Guglielmo Maria Caporale, Roman Matousek and Chris Stewart, Rating Assignments: Lessons from International Banks, April 2009

2619 Paul Belleflamme and Martin Peitz, Asymmetric Information and Overinvestment in Quality, April 2009

2620 Thomas Dohmen, Armin Falk, David Huffman and Uwe Sunde, Are Risk Aversion and Impatience Related to Cognitive Ability?, April 2009

2621 Yin-Wong Cheung and Xingwang Qian, The Empirics of China's Outward Direct Investment, April 2009

2622 Frédérique Bec and Christian Gollier, Assets Returns Volatility and Investment Horizon: The French Case, April 2009

2623 Ronnie Schöb and Marcel Thum, Asymmetric Information Renders Minimum Wages Less Harmful, April 2009

2624 Martin Ruf and Alfons J. Weichenrieder, The Taxation of Passive Foreign Investment Lessons from German Experience, April 2009

2625 Yao Li, Borders and Distance in Knowledge Spillovers: Dying over Time or Dying with Age? - Evidence from Patent Citations, April 2009

2626 Jim Malley and Ulrich Woitek, Technology Shocks and Aggregate Fluctuations in an Estimated Hybrid RBC Model, April 2009

2627 Jin Cao and Gerhard Illing, Endogenous Systemic Liquidity Risk, April 2009

2628 Thiess Buettner and Bjoern Kauder, Revenue Forecasting Practices: Differences across Countries and Consequences for Forecasting Performance, April 2009

2629 Håkan Selin, The Rise in Female Employment and the Role of Tax Incentives - An Empirical Analysis of the Swedish Individual Tax Reform of 1971, April 2009

2630 Nick Johnstone and Ivan Hascic, Environmental Policy Design and the Fragmentation of International Markets for Innovation, April 2009 
2631 Spiros Bougheas, Richard Kneller and Raymond Riezman, Optimal Education Policies and Comparative Advantage, April 2009

2632 Jay Pil Choi and Heiko Gerlach, Multi-Market Collusion with Demand Linkages and Antitrust Enforcement, April 2009

2633 Thor O. Thoresen, Income Mobility of Owners of Small Businesses when Boundaries between Occupations are Vague, April 2009

2634 Guido Schwerdt and Amelie C. Wuppermann, Is Traditional Teaching really all that Bad? A Within-Student Between-Subject Approach, April 2009

2635 Kurt R. Brekke, Luigi Siciliani and Odd Rune Straume, Hospital Competition and Quality with Regulated Prices, April 2009

2636 Peter Diamond, Taxes and Pensions, April 2009

2637 Shoshana Grossbard, How "Chicagoan" are Gary Becker's Economic Models of Marriage?, May 2009

2638 Roland Strausz, Regulatory Risk under Optimal Incentive Regulation, May 2009

2639 Holger Zemanek, Ansgar Belke and Gunther Schnabl, Current Account Imbalances and Structural Adjustment in the Euro Area: How to Rebalance Competitiveness, May 2009

2640 Harald Hau and Marcel Thum, Subprime Crisis and Board (In-)Competence: Private vs. Public Banks in Germany, May 2009

2641 Martin Halla, Mario Lackner and Friedrich G. Schneider, An Empirical Analysis of the Dynamics of the Welfare State: The Case of Benefit Morale, May 2009

2642 Balázs Égert, Infrastructure Investment in Network Industries: The Role of Incentive Regulation and Regulatory Independence, May 2009

2643 Christian Gollier, Expected Net Present Value, Expected Net Future Value, and the Ramsey Rule, May 2009

2644 Sören Blomquist and Håkan Selin, Hourly Wage Rate and Taxable Labor Income Responsiveness to Changes in Marginal Tax Rates, May 2009

2645 Dominique Demougin, Oliver Fabel and Christian Thomann, Implicit vs. Explicit Incentives: Theory and a Case Study, May 2009 